\title{
Dynamic Mechanical and Morphological Study on Model Pressure Sensitive Adhesive Based on Poly(styrene-b-butadiene-b-styrene)
}

\author{
Ick Kyung Sung, Kwang-Suk KIm,* and In-Joo CHIN*, \\ Research Institute, Kolon Chemical Co., Ltd., Inchon 404-250, Korea \\ * School of Chemical Science and Engineering, Inha University, Inchon 402-751, Korea
}

(Received May 26, 1997)

\begin{abstract}
Poly(styrene- $b$-butadiene- $b$-styrene) (SBS) was blended with a tackifier resin such as aliphatic resin, aromatic resin or hydrogenated dicyclopentadiene resin to form the model pressure sensitive adhesive (PSA), and the dynamic mechanical and morphological properties of these model PSAs were characterized. Compatibility of the SBS/tackifier resin blend was investigated by observing change in $T_{\mathrm{g}}$ and was substantiated by morphological observation. As the amount of the tackifier resin increased, the order-disorder transition temperature of the blend determined by analyzing the small-angle X-ray scattering profile was greatly reduced. However, $G^{\prime}$ of the SBS/tackifier blend either increased or decreased, depending on the compatibility. Dynamic mechanical and morphological properties of the blend were influenced by whether the tackifier was compatible with the polystyrene block or polybutadiene block of SBS.

KEY WORDS Model Pressure Sensitive Adhesive/Compatibility / (Poly(styrene- $b$-butadiene- $b$-styrene)/-

Tackifier Resin) Blend / Small-Angle X-Ray Scattering/Order-Disorder Transition Temperature /
\end{abstract}

Pressure sensitive adhesive (PSA) can be applied to various substrates with relatively little pressure and are easily removed without leaving any residue on the substrates. ${ }^{1}$ The main ingredients of a PSA include elastomer, tackifier, processing oil, filler and additives such as antioxidant and softener. Tackifier is a low molecular weight hydrocarbon, which improves the wettability and tackiness of the elastomer. The performance of a given PSA can be characterized by initial adhesion (tack), peel adhesion, and cohesion, which in turn are affected by the compatibility between elastomer and tackifier. $^{2}$

The relationship between compatibility and adhesive properties has been the subject of many studies. For example, Wetzel claimed that incompatibility between elastomer and tackifier, and the phase-separated structure of the PSA are required to produce high initial adhesion. ${ }^{3}$ However, recent studies by Sheriff using electron microscopy and dilatometry indicate that the natural rubber based PSA containing poly( $\beta$-pinene) or hydrogenated dicyclopentadiene (DCPD) as the tackifier forms a homogeneous phase. They also confirmed improved adhesive properties and showed the earlier results by Wetzel were not convincing. ${ }^{4,5}$ Kraus found that the compatibility between the tackifier and the diene block of the elastomer was necessary to give good initial adhesion. ${ }^{6-9}$ Class and Chu reported the compatibility was dependent upon the structural similarity, and the concentration and molecular weight of the tackifier. ${ }^{10}$ Akiyama investigated the phase behavior of poly(styrene$b$-isoprene- $b$-styrene) (SIS) based PSAs, ${ }^{11,12}$ and Sung and Chin reported rheological properties of some model PSAs. ${ }^{13}$

Most research on PSA so far has been directed at the PSA systems whose elastomer was the natural rubber or the block copolymers of polystyrene and polyisoprene. In this study, we blended poly(styrene- $b$-butadiene- $b$ styrene) (SBS) thermoplastic elastomer with tackifier to

\footnotetext{
+ To whom correspondence should be addressed.
}

form a model PSA and examined the morphological and dynamic mechanical characteristics of the model PSA. Aliphatic resin, aromatic resin and hydrogenated DCPD resin were used as the tackifier.

\section{EXPERIMENTAL}

\section{Preparation of Model PSA}

SBS (Kraton G-1101, $M_{n}=132,000 \mathrm{~g} \mathrm{~mol}^{-1}, M_{\mathrm{w}}=$ $153,000 \mathrm{~g} \mathrm{~mol}^{-1}$, polystyrene content $=30 \mathrm{wt} \%$ ) was provided by Shell, and tackifiers were donated by Kolon Chemical. SBS and tackifier were used without purification. Scheme 1 depicts the structure and Table I shows the molecular characteristics of the tackifiers. Model PSA was prepared by casting the elastomer/tackifier solution in toluene, which was dried at room temperature for 2

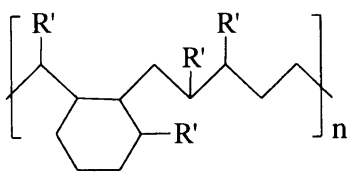

Aliphatic resin

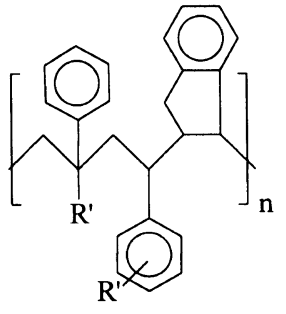

Aromatic resin

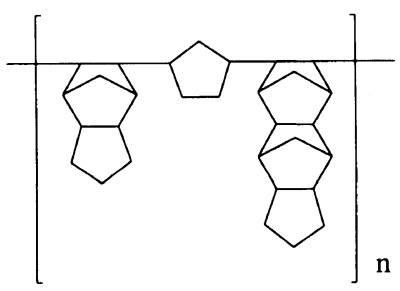

Hydrogenated DCPD resin

$$
\mathrm{R}^{\prime}=\mathrm{CH}_{3}
$$

Scheme 1. Structures of various tackifiers. 
Table I. Characteristics of tackifier resins

\begin{tabular}{|c|c|c|c|}
\hline \multirow{2}{*}{ Tackifier } & $M_{n}$ & \multirow{2}{*}{$M_{w} / M_{n}$} & $T_{\mathrm{g}}$ \\
\hline & $\mathrm{g} \mathrm{mol}^{-1}$ & & ${ }^{\circ} \mathrm{C}$ \\
\hline Aliphatic resin & 779 & 2.48 & 57 \\
\hline Aromatic resin & 646 & 1.87 & 63 \\
\hline Hydrogenated DCPD resin & 250 & 1.97 & 56 \\
\hline
\end{tabular}

weeks and further dried in vacuum at $40^{\circ} \mathrm{C}$ for 1 week. The samples were annealed at $120^{\circ} \mathrm{C}$ for $2 \mathrm{~h}$ in vacuum to eliminate thermal history. Dynamic mechanical properties and $T_{\mathrm{g}}$ of the model PSA films were measured by a rheometer (RDS II, Rheometrics) using a parallel plate geometry $(8 \mathrm{~mm}$ in diameter) within the linear viscoelastic region ( $1 \%$ strain, $\left.1 \mathrm{rad} \mathrm{s}^{-1}\right)$ between 100 and $120^{\circ} \mathrm{C}$. $T_{\mathrm{g}}$ of the tackifier resin was measured by DSC (PL-DSC, Rheometrics) at a heating rate of $10^{\circ} \mathrm{C} \mathrm{min}^{-1}$, because the tackifier resin was too brittle to be measured by rheometry.

\section{Characterization of Model PSA}

Order-disorder transiton temperature $\left(T_{\mathrm{ODT}}\right)$ of the SBS/tackifier blend film ( $2 \mathrm{~mm}$ thick) was determined by analyzing small angle X-ray scattering data collected by synchrotron radiation at Pohang Light Source (PLS, Beamline 3C2) in Pohang, Korea. The wavelength of $\mathrm{X}$-ray was $1.608 \AA$, as determined by a Si(III) double crystal monochromator. ${ }^{14}$ The scattering intensity of the sample was measured at each predetermined temperature by a photodiode array detector (1024 pixels inch $\left.^{-1}\right)$, while the sample was heated at a rate of $5^{\circ} \mathrm{C} \mathrm{min}^{-1}$ from room temperature to the desired temperature. SBS was found stable up to $400^{\circ} \mathrm{C}$ by TGA. The distance between the sample and detector was $105 \mathrm{~cm}$ and the sample was scanned for $6 \mathrm{~s}$ at each temperature. When the raw scattering profile was corrected against parasitic scattering and thermal fluctuation, $T_{\text {ODT }}$ was obtained by the Leibler theory based on the random phase approximation. ${ }^{15,16}$ The order-disorder transition we observed was a thermally induced microphase transition, which resulted from the structural evolution of the microstructure in the block copolymer during heating. Therefore, the order-disorder transition temperature measured by the time-resolved syncrotron SAXS could be affected by the heating/cooling condition. Microscopic phase structure of the SBS/tackifier blend was investigated by TEM. Samples were stained in $\mathrm{OsO}_{4}$ for $24 \mathrm{~h}$, microtomed, and viewed at an accelerating voltage of $200 \mathrm{kV}$.

To measure the peel strength of the model PSA the SBS/tackifier blend solution (in toluene: solid content = $50 \mathrm{wt} \%$ ) was coated on the oriented polypropylene film. $180^{\circ}$ peel strength of the blend was measured according to the KS A-1107, after drying the blend film at $100^{\circ} \mathrm{C}$ for $2 \mathrm{~min}$. The $\mathbf{J}$. Dow rolling ball tack test method was used to obtain tack or initial adhesion of the model PSA tape. $^{2}$

\section{RESULTS AND DISCUSSION}

As the amount of the tackifier in the model PSA (the

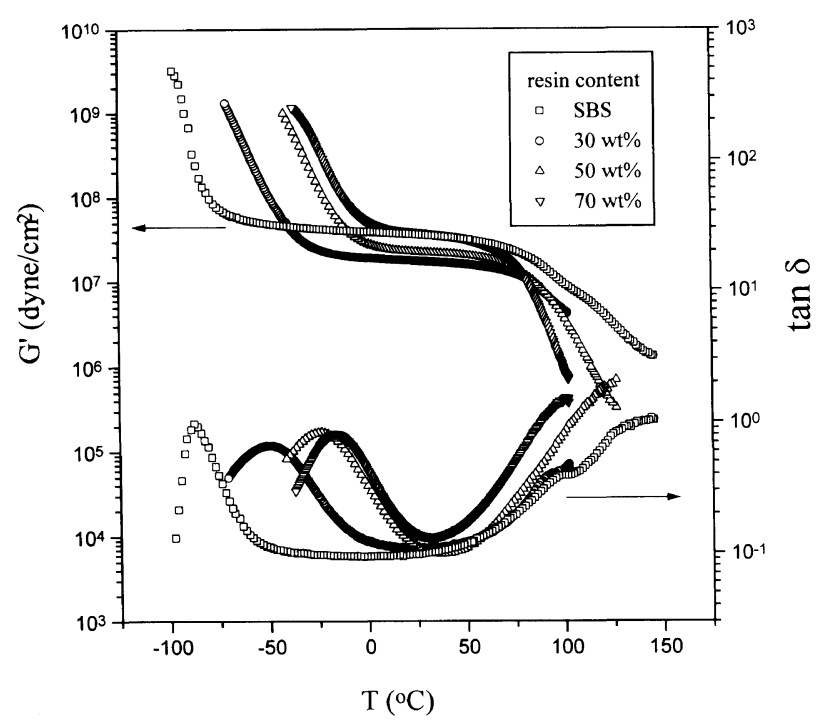

Figure 1. $G^{\prime}$ and $\tan \delta$ of SBS/aliphatic resin blend at $1 \mathrm{rads}^{-1}$.

$\mathrm{SBS} /$ tackifier resin blend) increased, $G^{\prime}$ of the SBS/tackifier blend increased when the tackifier was compatible with the polystyrene block, not with the polybutadiene block, of SBS and when the blend became phase-separated due to the incompatibility between the tackifier and SBS. Holden ${ }^{17}$ utilized the following relationship for the poly(styrene- $b$-diene) block copolymer where the polystyrene domains were assumed to be dispersed in the continuous polydiene matrix.

$$
G_{\mathrm{N}}^{\infty}=\left(\rho R T / M_{\mathrm{e}}\right)\left(1+2.5 c+14.1 c^{2}\right)
$$

where $G_{\mathrm{N}}^{\infty}$ is the plateau modulus of the copolymer, $\rho$ is the density, $R$ is the gas constant, $T$ is the temperature, $M_{\mathrm{e}}$ is the critical molecular weight for entanglement, and $c$ is the concentration of polystyrene microdomains dispersed in the block copolymer. This relationship can be applied to the blend of the tackifier and SBS copolymer. If the tackifier is immiscible with the SBS block copolymer or if the tackifier is miscible with the polystyrene block of the block copolymer, $c$ becomes higher and the plateau modulus of the blend increases.

In Figure 1 the rubbery plateau modulus of the SBS/aliphatic resin blend is lower than that of SBS throughout the tackifier concentration, partly due to the compatibility of aliphatic resin and the polybutadiene block of SBS. However, the rubbery plateau modulus gradually increased with concentration of the aliphatic resin, which may indicate compatibility is somewhat limited. This is clearly shown in Table II, which compares $T_{\mathrm{g}}$ of the polybutadiene block of SBS with theoretical $T_{\mathrm{g}}$ based on the Fox equation. The agreement is fairly good until the aliphatic resin content is $50 \mathrm{wt} \%$, and it becomes poor when the resin content is higher than $50 \mathrm{wt} \%$. The blend may thus have a phase separated microstructure except for some tackifier concentrations.

Figure 2 shows $G^{\prime}$ and $\tan \delta$ of the SBS/aromatic resin blends as a function of temperature. Regardless of the tackifier concentration $G^{\prime}$ of the blends were higher than that of SBS alone, which suggests aromatic resin is compatible with the polystyrene block of SBS. In Table II as the concentration of aromatic resin in the blend increases, the $T_{\mathrm{g}}$ of the polystyrene block of SBS 
Table II. $T_{\mathrm{g}}$ and $T_{\text {ODT }}$ of various SBS/tackifier resin blends

\begin{tabular}{|c|c|c|c|c|}
\hline \multirow[b]{2}{*}{ Sample } & \multicolumn{2}{|c|}{$T_{\mathrm{g}}$ of $\mathrm{SBS} /{ }^{\circ} \mathrm{C}$} & \multirow{2}{*}{$\begin{array}{c}\text { Theoretical } \\
T_{\mathrm{g}}{ }^{\mathrm{a}} /{ }^{\circ} \mathrm{C}\end{array}$} & \multirow[b]{2}{*}{$T_{\mathrm{ODT}} /{ }^{\circ} \mathrm{C}$} \\
\hline & $\begin{array}{c}\text { Polybutadiene } \\
\text { block }\end{array}$ & $\begin{array}{l}\text { Polystyrene } \\
\text { block }\end{array}$ & & \\
\hline SBS & -88 & 98 & - & 326 \\
\hline \multicolumn{5}{|c|}{ SBS/Aliphatic resin blend } \\
\hline $70 / 30$ & -50 & 90 & -53 & 149 \\
\hline $50 / 50$ & -35 & - & -30 & 130 \\
\hline $30 / 70$ & -16 & - & -1 & 109 \\
\hline \multicolumn{5}{|c|}{ SBS/Aromatic resin blend } \\
\hline $70 / 30$ & -68 & 76 & 86 & 162 \\
\hline $50 / 50$ & - & 72 & 79 & 101 \\
\hline \multicolumn{5}{|c|}{ SBS Hydrogenated DCPD resin blend } \\
\hline $70 / 30$ & -40 & 90 & -60 & 90 \\
\hline $50 / 50$ & -2 & - & -37 & - \\
\hline $30 / 70$ & 19 & - & -6 & - \\
\hline
\end{tabular}

${ }^{a}$ Calculated by the Fox equation.

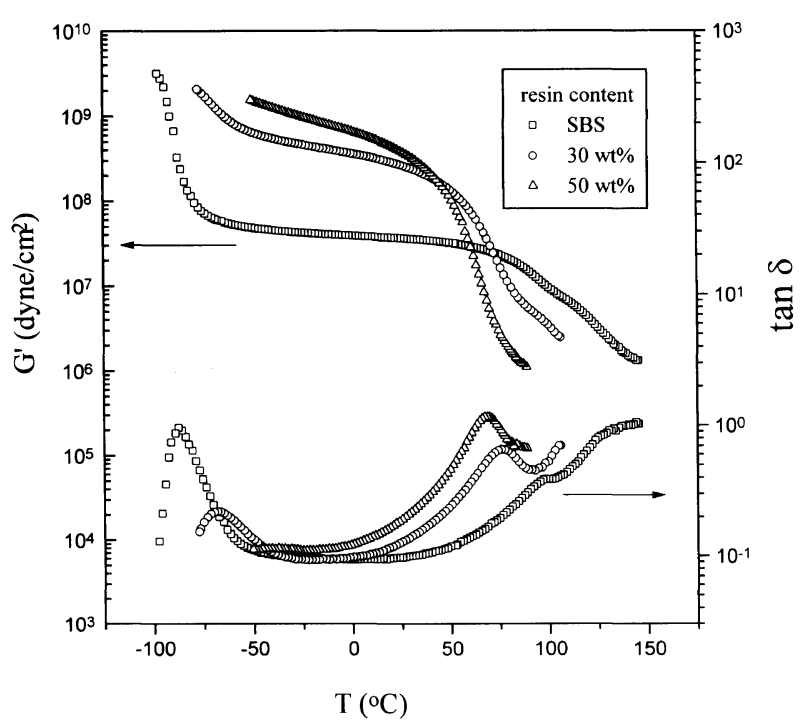

Figure 2. $G^{\prime}$ and $\tan \delta$ of SBS/aromatic resin blend at $1 \mathrm{rad} \mathrm{s}^{-1}$.

decreases. Experimental $T_{\mathrm{g}}$ of the polystyrene block of the blend correlated reasonably well with calculated values using the Fox equation.

$G^{\prime}$ and $\tan \delta$ of the SBS/hydrogenated DCPD blends are shown in Figure 3. Contrary to other blends, $G^{\prime}$ of the SBS/hydrogenated DCPD blends decreased, as the concentration of the hydrogenated DCPD increased, and $G^{\prime}$ of the blend was always lower than that of SBS. This may be because hydrogenated DCPD resin is compatible with the polybutadiene block of SBS. Han reported similar results for the blends of modified polyterpene and SBS. ${ }^{18} T_{\mathrm{g}}$ of the polybutadiene block of SBS did not agree well with the theoretical predictions based on the Fox equation, as shown in Table II. We could not confirm solely from the dynamic mechanical measurement that hydrogenated DCPD resin is compatible with the polybutadiene block of SBS.

Time-resolved small angle X-ray scattering profiles of SBS and SBS/aromatic resin blend are shown as a function of temperature in Figure 4. SBS maintained

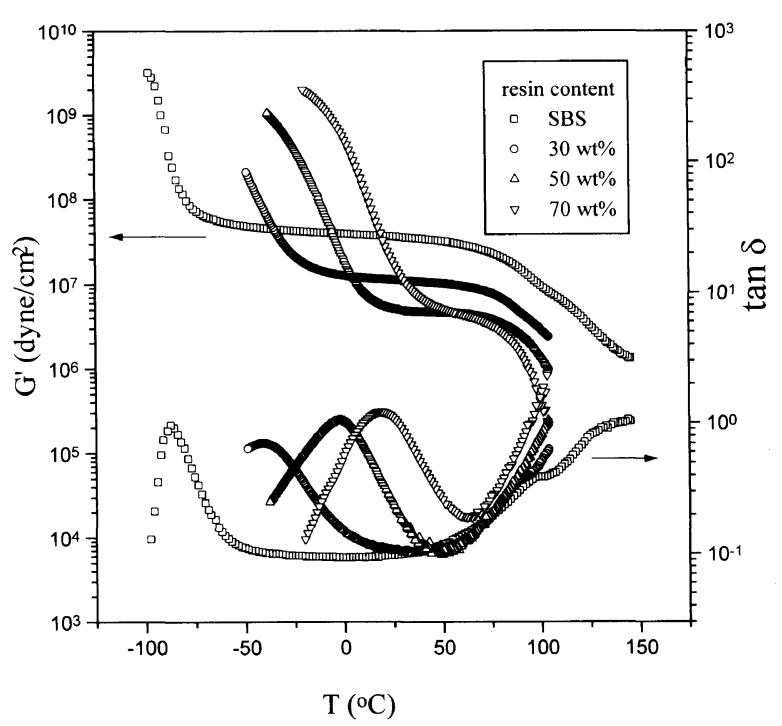

Figure 3. $G^{\prime}$ and $\tan \delta$ of SBS/hydrogenated DCPD resin blend at $1 \mathrm{rad} \mathrm{s}^{-1}$.
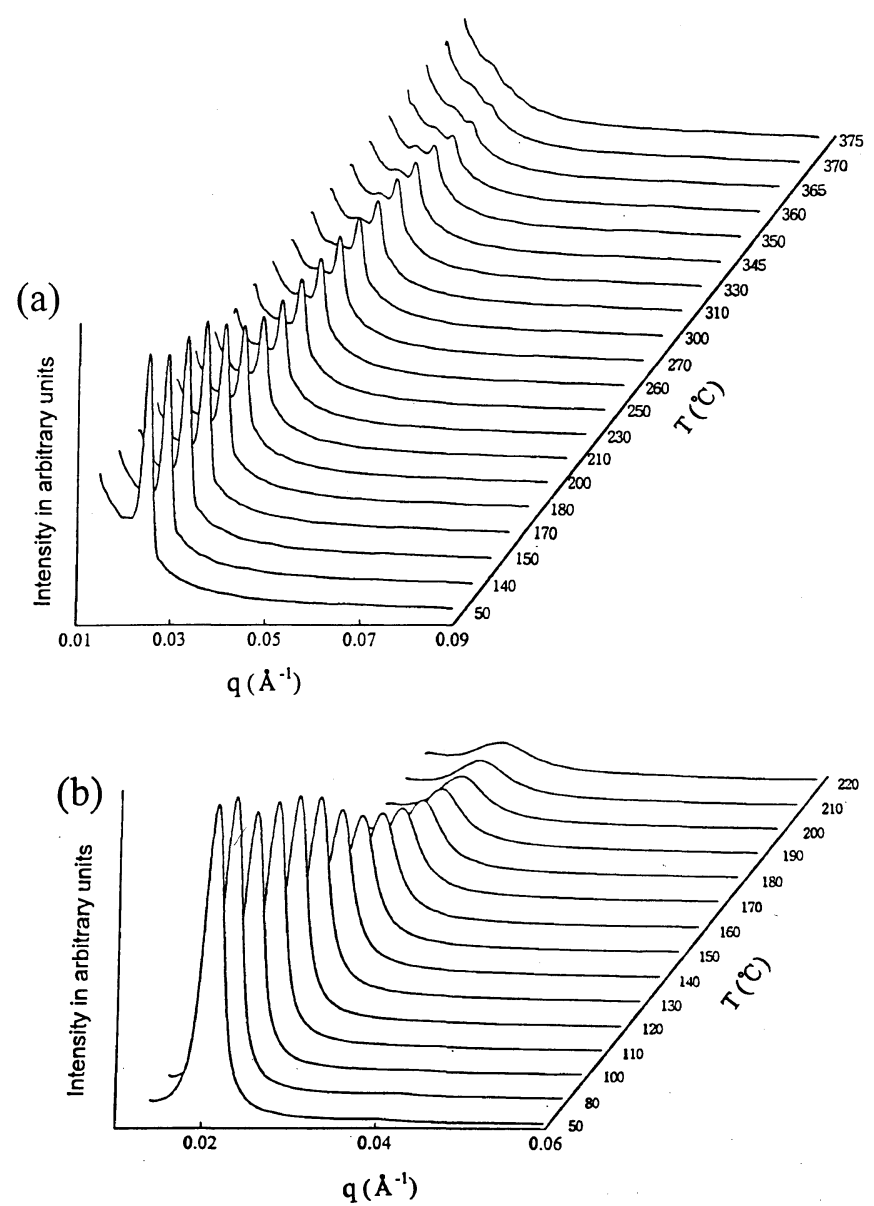

Figure 4. Time-resolved SAXS profile: (a) SBS and (b) 70/30 SBS/aromatic resin blend.

ordered microstructure from ambient temperature up to around $360^{\circ} \mathrm{C}$, showing the scattering maximum, in Figure 4(a). As the temperature increased, the scattering intensity gradually decreased and scattering maximum disappeared eventually resulting in a disordered microstructure. For the SBS/aromatic resin blend in Figure 4(b), the same as noted. Compared with SBS, the scat- 




Figure 5. $1 / I_{\max }$ as a function of $1 / T$ of SBS and SBS/aromatic resin blend.

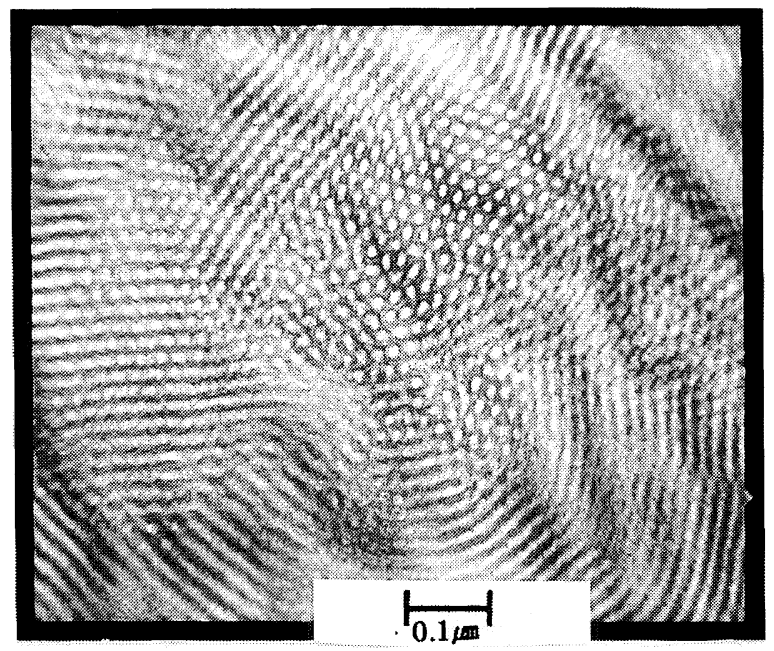

Figure 6. TEM micrograph of SBS.

tering intensity of the blend was reduced significantly and the onset temperature, at which the blend begins to form a homogeneous disordered structure by losing the scattering maximum, became much lower. The inverse of maximum scattering intensity $\left(I_{\max }\right)$ is plotted against $1 / T$ in Figure 5. For all blends there was a linear relationship between $1 / I_{\max }$ and $1 / T$ at high temperatures, and as the temperature decreased, $1 / T_{\max }$ started to deviate from the linear relationship with $1 / T$. According to Leibler's theory, the order-disorder transition temperature is characterized by the onset of the deviation from such linearity. Table II lists the $T_{\mathrm{ODT}}$ of the various SBS/tackifier blends thus obtained. In comparison with the $T_{\text {ODT }}$ of SBS, $T_{\text {ODT }}$ of the SBS/tackifier blend was suppressed, and in particular the SBS/hydrogenated DCPD resin blend showed the most decrease in $T_{\text {ODT }}$. In general $T_{\text {ODT }}$ of a block copolymer depends on interactions and molecular weights of the blocks. $T_{\mathrm{ODT}}$ of the $\mathrm{SBS} /$ tackifier blend is expected to decrease when the tackifier resin is mixed with SBS. Thus, the SBS/hydrogenated DCPD resin blend may be more compatible than others.

Morphology of the model PSA was investigated by


Figure 7. TEM micrographs of SBS/aliphatic resin blends: (a) 80/20 and (b) $50 / 50$.

TEM to confirm the compatibility of SBS and tackifier by substantiating mechanical data. It is difficult to conclude from the dynamic mechanical measurement alone that the tackifier is compatible with the polystyrene block or the polybutadiene block of SBS. Because SBS used in this study contained $30 \mathrm{wt} \%$ of polystyrene, the microstructure of SBS was assumed to be cylindrical, which was confirmed by TEM as shown in Figure 6. In Figure 7 when the blend contained $20 \mathrm{wt} \%$ aliphatic resin, the cylindrical microstructure of SBS was maintained, while the blend containing $50 \mathrm{wt} \%$ aliphatic resin showed discrete domains of the tackifier. Aliphatic resin may thus have limited compatibility with the polybutadiene block of SBS. The SBS/aromatic resin blend presented a rather disordered microstructure without any discrete domains when the aromatic resin content was $20 \mathrm{wt} \%$ (Figure 8(a)), and as the tackifier concentration increased to $70 \mathrm{wt} \%$ (Figure $8(\mathrm{~b})$ ), the structure remained disordered. Similar results were obtained by Han. ${ }^{19,20}$ Thus, we may conclude that aromatic resin is compatible with the polystyrene block of SBS, because the SBS/ aromatic resin blend did not show discrete domains. That is further supported by the fact that the $T_{\mathrm{g}}$ of the polystyrene block of SBS is affected by the blending and 

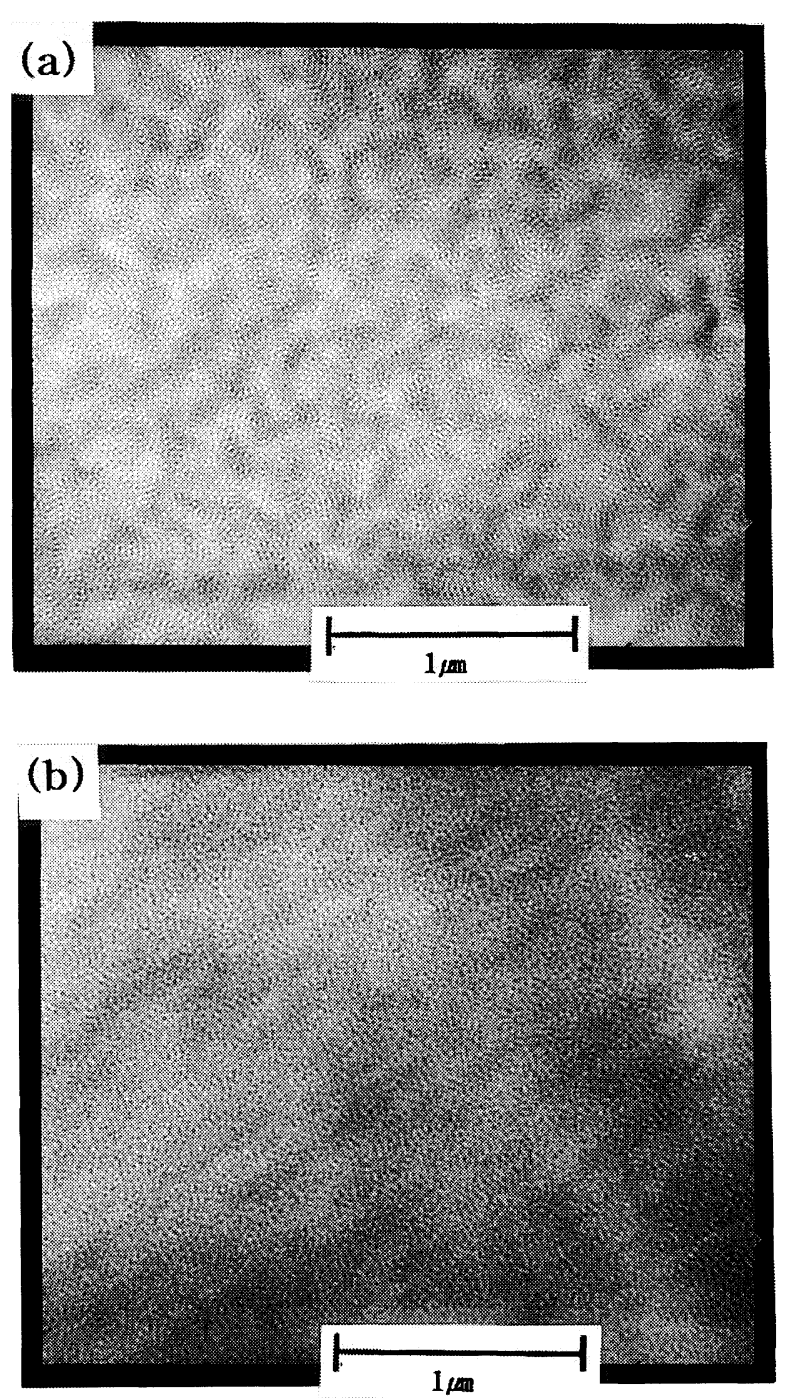

Figure 8. TEM micrographs of SBS/aromatic resin blends: (a) $80 / 20$ and (b) $30 / 70$

$G^{\prime}$ increases as a result of blending.

It would be meaningful to compare peel strength of various blends, because PSA performance such as peel strength is governed by viscoelastic and surface chemical properties of the PSA, which in turn are influenced by the microphase structure of the PSA. Peel strength is expected to be affected largely by the polystyrene block rather than the polybutadiene block of SBS. Since aromatic resin is compatible with the polystyrene block of SBS, the SBS/aromatic resin blend showed the highest peel strength as anticipated (Table III). Hydrogenated DCPD resin is believed to be completely compatible with
Table III. Peel strength of various blends (SBS : tackifier $=50: 50$ by weight)

\begin{tabular}{lc}
\hline \multicolumn{1}{c}{ Tackifier } & Peel strength $(\mathrm{g} / 25 \mathrm{~mm})$ \\
\hline Aliphatic resin & 750 \\
Aromatic resin & 2150 \\
Hydrogenated resin & 1200 \\
\hline
\end{tabular}

the polybutadiene block of SBS throughout the blend composition. $G^{\prime}$ of the SBS/hydrogenated DCPD resin blend was lower than that of SBS and $T_{\text {ODT }}$ of the blend was greatly reduced. Hydrogenated DCPD resin is believed to act as a very effective tackifier for SBS elastomer, because it is not only compatible with SBS but also lowers $G^{\prime}$ of SBS.

Acknowledgments. Experiments at Pohang Light Source were supported by MOST and POSCO in Korea. Authors greatly acknowledge the financial support of Inha University (1996-1997).

\section{REFERENCES}

1. H. Kim and H. Mizumachi, J. Appl. Polym. Sci., 56, 201 (1995).

2. D. Satas, in "Handbook of Pressure Sensitive Adhesive Technology," 2nd ed, D. Satas, Ed., Van Nostrand Reinhold, New York, N.Y., 1989.

3. F. H. Wetzel, Rubber Age, 7, 28 (1964).

4. M. Sheriff, Ph. D. Thesis, Council for National Academic Awards, London, 1973.

5. M. Sheriff, R. W. Knibbs, and P. G. Langley, J. Appl. Polym. Sci., 17, 3423 (1973).

6. G. Kraus, F. B. Jones, O. L. Marras, and K. W. Rollman, J. Adhesion, 8, 235 (1977)

7. G. Kraus and K. W. Rollman, J. Appl. Polym. Sci., 21, 3311 (1977).

8. G. Kraus, K. W. Rollman, and R. A. Gray, J. Adhesion, 10, 221 (1979).

9. G. Kraus and T. Hashimoto, J. Appl. Polym. Sci., 27, 1745 (1982).

10. J. B. Class and S. G. Chu, J. Appl. Polym. Sci., 30, 805 (1985).

11. S. Kawahara, S. Akiyama, and Y. Kano, Polymer, 32, 1618 (1991).

12. S. Kawahara and S. Akiyama, Macromolecules, 26, 2428 (1993).

13. I. K. Sung and I. Chin, Korea Polym. J., 5, 67 (1997).

14. B. J. Park, S. Y. Rah, Y. J. Park, and K. B. Lee, Rev. Sci. Instrum., 66, 1722 (1995).

15. L. Leibler, Macromolecules, 15, 1283 (1982).

16. N. Sakamoto and T. Hashimoto, Macromolecules, 28, 6825 (1995).

17. G. Holden, "Block and Graft Polymerization," R. J. Ceresa, Ed., Wiley, New York, N.Y., 1973, Chapter 6.

18. C. D. Han, J. Kim, and D. M. Baek, J. Adhesion, 28, 201 (1989).

19. C. D. Han, D. M. Baek, and J. Kim, Macromolecules, 25, 3052 (1992).

20. K. Kimishima, T. Hashimoto, and C. D. Han, Macromolecules, 28, 3842 (1995). 